\title{
Cardiopulmonary resuscitation and automatic external defibrillator training in schools: "Is anyone learning how to save a life?"
}

\author{
Devin Hart, BSc ${ }^{*}$; Oscar Flores-Medrano, BSc ${ }^{*}$; Steve Brooks, MD, MSc ${ }^{\S \|}$; Jason E. Buick, BScK*ף; \\ Laurie J. Morrison, MD, MSc ${ }^{* \Phi \# \# ~}$
}

\section{ABSTRACT}

Objectives: Bystander resuscitation efforts, such as cardiopulmonary resuscitation (CPR) and use of an automatic external defibrillator (AED), save lives in cardiac arrest cases. School training in CPR and AED use may increase the currently low community rates of bystander resuscitation. The study objective was to determine the rates of CPR and AED training in Toronto secondary schools and to identify barriers to training and training techniques.

Methods: This prospective study consisted of telephone interviews conducted with key school staff knowledgeable about CPR and AED teaching. An encrypted Web-based tool with prespecified variables and built-in logic was employed to standardize data collection.

Results: Of 268 schools contacted, $93 \%$ were available for interview and $83 \%$ consented to participate. Students and staff were trained in CPR in $51 \%$ and $80 \%$ of schools, respectively. Private schools had the lowest training rate $(39 \%)$. Six percent of schools provided AED training to students and $47 \%$ provided AED training to staff. Forty-eight percent of schools had at least one AED installed, but $25 \%$ were unaware if their AED was registered with emergency services dispatch. Cost (17\%), perceived need (11\%), and school population size $(10 \%)$ were common barriers to student training. Frequently employed training techniques were interactive $(32 \%)$, didactic instruction $(30 \%)$ and printed material (16\%).

Conclusions: CPR training rates for staff and students were moderate overall and lowest in private schools, whereas training rates in AED use were poor in all schools. Identified barriers to training include cost and student population size (perceived to be too small to be cost-effective or too large to be implemented). Future studies should assess the application of convenient and cost-effective teaching alternatives not presently in use.

RÉSUMÉ

Objectifs: Les manœuvres de réanimation effectuées par les témoins, telles que la réanimation cardiorespiratoire $(R C R)$ et I'utilisation du défibrillateur externe automatique (DEA), peuvent sauver la vie dans les cas d'arrêt cardiaque. Enseigner, dans les écoles, la RCR et l'utilisation du DEA peut augmenter les faibles taux de réanimation effectuée par les témoins, enregistrés au moment de l'étude dans les collectivités. L'étude visait à déterminer les taux de formation sur la RCR et I'utilisation du DEA dans les écoles secondaires à Toronto et à cerner les obstacles à la formation et aux techniques de formation.

Méthode: II s'agit d'une étude prospective, qui consistait en des entrevues téléphoniques et qui a été menée parmi des membres importants du personnel, bien au fait de la formation sur la RCR et l'utilisation du DEA. Nous avons utilisé un outil Web, encodé, comportant des variables prédéterminées et doté d'une fonction logique intégrée pour uniformiser la collecte de données.

Résultats: Sur 268 écoles avec lesquelles nous avons communiqué, $93 \%$ ont fait écho à la demande d'entrevue et $83 \%$ ont accepté d'y participer. Les élèves et le personnel ont reçu une formation en RCR dans $51 \%$ et $80 \%$ des écoles, respectivement. Le taux le plus faible $(39 \%)$ de formation a été enregistré dans les écoles privées. Une formation sur I'utilisation du DEA a été donnée aux élèves dans $6 \%$ des écoles et au personnel dans $47 \%$ des écoles. Un DEA, au moins, a été installé dans $48 \%$ des écoles, mais, dans $25 \%$ d'entre elles, on ne savait pas si le DEA était inscrit dans un

From *Rescu, Keenan Research Centre, Li Ka Shing Knowledge Institute, and St. Michael's Hospital, University of Toronto, Toronto, ON; †Faculty of Science, McGill University, Montreal, QC; łFaculty of Science, Western University, London, ON; §Division of Emergency Medicine, Department of Medicine, University of Toronto, Toronto, ON; \|Department of Emergency Medicine, Queen's University, Kingston, ON; $\uparrow$ Department of Health Policy, Management and Evaluation, University of Toronto, Toronto, ON; and \#Department of Emergency Services, St Michael's Hospital, Toronto, ON.

Correspondence to: Dr. Laurie Morrison, Rescu, Keenan Research Centre, Li Ka Shing Knowledge Institute, St. Michael's Hospital, 30 Bond Street, Toronto, ON M5B 1W8; morrisonl@smh.ca.

This article has been peer reviewed.

(c) Canadian Association of Emergency Physicians

$270 \quad 2013 ; 15(5)$
CJEM 2013:15(5):270-278

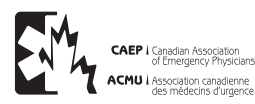

DOI 10.2310/8000.2013.130898

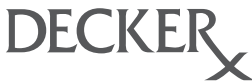


centre de répartition des services de secours. Les coûts $(17 \%)$, la faible perception du besoin $(11 \%)$, et la taille de la population scolaire $(10 \%)$ se sont révélés des obstacles fréquents à la formation des élèves. Les techniques de formation comprenaient souvent des applications interactives $(32 \%)$, de l'enseignement didactique $(30 \%)$, et des documents imprimés (16\%).

Conclusions: Dans l'ensemble, les taux de formation sur la RCR à l'intention du personnel et des élèves étaient moyens, et les taux les plus faibles ont été enregistrés dans les écoles privées, mais les taux de formation sur l'utilisation du DEA étaient faibles dans toutes les écoles. Les obstacles à la formation qui se sont dégagés de l'étude étaient les coûts et la taille de la population scolaire (perçue comme trop petite pour que la formation soit rentable ou trop grande pour que la formation puisse être donnée). II faudrait évaluer, dans d'autres études, l'application de solutions de rechange, pratiques et rentables, aux méthodes habituelles d'enseignement, non encore appliquées.

Keywords: automatic external defibrillation, bystander resuscitation, cardiac arrest, classroom-based education, education, self-directed education
In Canada, the incidence of cardiac arrest varies between 55 and 59 per 100,000 people. ${ }^{1}$ Survival rates from an out-of-hospital cardiac arrest (OHCA) continue to be only about $5 \% .{ }^{1-3}$ This low survival rate can, in part, be attributed to a failure to act. A large population-based cohort study conducted in Canada and the United States noted the rate of cardiopulmonary resuscitation $(\mathrm{CPR})$ and automatic external defibrillator (AED) application by bystanders to be as low as $32 \%$ and $2 \%$ of cases, respectively. ${ }^{3}$ Low rates of bystander assistance may be attributed to the inability to recognize cardiac arrest. ${ }^{4}$

The "Chain of Survival" emphasizes calling 911, early CPR, and early defibrillation as the first three links of the chain ${ }^{5,6}$ [see Figure 1]. Bystander $\mathrm{CPR}^{7-15}$ and application of an $\mathrm{AED}^{3,10,12,16}$ have been shown to increase survival in an OHCA from 7 to $22 \%,{ }^{3}$ increasing to as high as $38 \%$ when a shock is delivered by an AED.,12 The effect of CPR and defibrillation decreases significantly with each minute that passes without intervention. ${ }^{10}$ In 2005, significant changes were made to CPR guidelines to simplify training for lay responders. ${ }^{5}$ Despite these changes, the rates of bystander CPR remain unchanged at $31 \%$ across Canadian and US regions. ${ }^{2}$

Bystander reluctance to perform CPR has been attributed to panicking (38\%) and fear of improper application $(9 \%) .{ }^{17}$ Fear of injury to the patient $(1 \%)$, reluctance to perform mouth-to-mouth breaths (1\%), and fear of communicable disease (e.g., human immunodeficiency virus [HIV]) were rarely cited as deterrents to bystanders from performing CPR. ${ }^{17}$ This suggests that comfort and training in CPR, not a willingness to perform CPR, are the limiting factors. ${ }^{17,18} \mathrm{CPR}$ and AED training for the general population may address many of these issues ${ }^{2,18-25}$ and increase bystander CPR and AED application rates, which we know directly improve survival rates. ${ }^{2}$

The secondary school system offers CPR and AED training to a high percentage of the population ${ }^{19,26,27}$ who might witness an arrest, given that about $78 \%$ of cardiac arrests occur in the home. ${ }^{1}$ According to the Ontario Ministry of Education, for students to receive their Ontario Secondary School Diploma (OSSD), they must complete one credit in physical education. ${ }^{28}$ Typically, students will complete this credit in grade 9, during which they must "demonstrate an understanding of cardiopulmonary resuscitation." 29

In Canada, legislation on AED training or AED installation in public buildings is lacking in all provinces except Manitoba. Charitable organizations and private foundations are working to have AEDs installed in schools across Ontario. In the event of a cardiac arrest occurring at a school, registration of a school's AED can aid emergency medical services (EMS) dispatchers in directing callers to the AED and coaching them to use it. Furthermore, education on CPR and AED training in schools will increase public awareness and could lead to a cultural change.

The primary objective of this study was to determine the CPR and AED training rates for both staff and students across all secondary schools in Toronto, Canada. Secondary objectives were to 1) report perceived barriers to training and common training

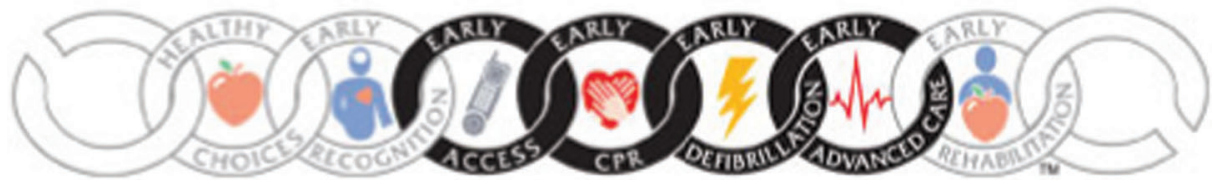

$C J E M \cdot J C M U$
Figure 1. Heart and Stroke Foundation of Canada Chain of Survival. 
techniques for both CPR and AED education and 2) report the presence and location of AEDs as well as their rate of AED registration with local EMS dispatch.

\section{METHODS}

\section{Study design}

A prospective telephone survey was conducted of all Toronto secondary schools from June 2009 to October 2009. Trained interviewers carried out telephone interviews with individuals who were identified as the most knowledgeable on the subject to obtain specific information about the school's CPR and AED training status.

The Research Ethics Board at St. Michael's Hospital in Toronto approved this study.

\section{Study setting and population}

The study population included all 268 Toronto secondary schools. The Toronto school system is composed of a private (independent school) system and a public system with two boards: the Toronto District School Board and the Toronto Catholic District School Board. A complete list of Toronto secondary public and private schools was obtained through the Ministry of Education, which maintains a current database of all registered secondary schools in the province. It was assumed that because schools must be registered with the Ministry of Education to provide the OSSD that this database would be the most complete and up-to-date source. Secondary schools were defined as schools educating grades 9 and above.

\section{Survey design}

The survey had five sections: AED information/status, staff CPR training, student CPR training, staff AED training, and student AED training. For schools that did not have an AED installed or did not offer training in either CPR or AED use, barriers for both installation and training were identified. Demographic data were also collected from each school.

\section{Survey implementation}

Schools were notified of the survey by regular mail prior to contact. At first contact, the key school individual(s) involved in the training was identified and oral consent was obtained. Telephone surveys were conducted by one of eight trained interviewers. Interviewers took part in a 2-day training course that included group-monitored mock calls with experienced researchers. Prepared scripts were used for first contact, identification of key individuals, and oral consent. All calls made by the interviewers were documented in call logs. Nonresponders were contacted up to five times before the principal investigator called the school administrator (school principal, chairman of the board) directly to ask for assistance.

\section{Data collection}

Data were entered during the interview into a standardized encrypted Web-based tool by the interviewer (Appendix). Web-based data entry provided prespecified variable responses, built-in logic, and error checks to minimize subjective, incomplete, and erroneous entries. Answers that did not conform to prespecified variable responses were recorded verbatim via text entry and later categorized by a single investigator (D.H.).

\section{RESULTS}

\section{Demographics and study population}

In the city of Toronto, there are 268 schools providing education to approximately 120,000 students and employing 13,000 teaching staff. Of the 268 schools that were contacted, $250(93 \%)$ responded and 223 (83\%) consented to participate. From the 223 schools that participated, $95(43 \%)$ were from the public school system, 32 (14\%) were from the Toronto Catholic schools, and 96 (43\%) were independent schools (Table 1).

\section{Primary outcomes}

Fifty-one percent of schools trained their students in CPR and $6 \%$ of schools trained their students to use an AED. Student CPR and AED training rates were lowest in the independent schools $(28 \%$ and $2 \%$, respectively). Most schools (80\%) train their staff in CPR, and almost half $(47 \%)$ train their staff in AED use (Table 2). 
CPR and AED training in schools

\begin{tabular}{|c|c|c|c|c|}
\hline & Public $n(\%)$ & Catholic public $n(\%)$ & Privaten $n(\%)$ & Total \\
\hline \multicolumn{5}{|l|}{ School demographics } \\
\hline Total & $107(40)$ & $32(12)$ & $129(48)$ & 268 \\
\hline Schools participating & $95(43)$ & $32(14)$ & $96(43)$ & 223 \\
\hline \multicolumn{5}{|l|}{ Population } \\
\hline Staff & $5,962(50)$ & $3,264(28)$ & $2,594(22)$ & 11,820 \\
\hline Students ( $\geq$ grade 9 ) & $75,525(64)$ & $27,482(23)$ & $15,351(13)$ & 118,358 \\
\hline Students & $78,335(59)$ & $29,607(22)$ & $25,148(19)$ & 133,090 \\
\hline
\end{tabular}

\section{Secondary outcomes}

Major barriers to student CPR and AED training were cost $(17 \%)$, no perceived need (11\%), and population size (either too small to be cost-effective or too large to be implemented) (10\%). Common barriers to staff CPR and AED training were none (25\%), lack of demand or low priority (17\%), school population size (either too small to be cost-effective or too large to be implemented) (15\%), and cost (10\%). The most common training techniques for both staff and student CPR/AED training were interactive (e.g., role playing, mannequin use), didactic speaker, and written materials. Very few schools used computer programs, Webbased software, or self-directed learning options for training (Table 3).

At least one AED was present in $48 \%$ of schools. The lowest frequency of AED installation was observed in the independent schools (18\%) and the highest in the public schools (83\%). AEDs were most commonly located in administrative offices (46\%), athletic facilities (19\%), and hallways (13\%). Most schools had signs indicating the location of the AED
$(78 \%)$, and most were installed in plain view (92\%). In schools without an AED installed, the most common barriers to installation were no reason at all (18\%), school population too small to be cost-effective (15\%), lack of interest or low priority (15\%), and lack of funds (10\%). Most schools (72\%) that had an AED were already registered with EMS dispatch. However, a significant number of schools $(25 \%)$ were unaware of the registration status of their AED. Follow-up visits with the schools with AEDs that lacked registration with the local EMS dispatch were conducted, and we confirmed universal AED registration with EMS dispatch.

\section{INTERPRETATION}

This study demonstrates that despite compulsory CPR education in the curriculum set by the Ontario Ministry of Education, such education was far from universal. Generally, a higher proportion of Toronto high schools ensured that staff received CPR training and AED training. Independent schools provided training less frequently to both staff and students in CPR and AED use. Traditional teaching styles are

\begin{tabular}{|c|c|c|c|c|}
\hline & $\begin{array}{c}\text { Public }(n=95) \\
n(\%)\end{array}$ & $\begin{array}{l}\text { Catholic public } \\
(n=32), n(\%)\end{array}$ & $\begin{array}{c}\text { Private }(n=96) \\
n(\%)\end{array}$ & $\begin{array}{c}\text { Total }(N=223), \\
n(\%)\end{array}$ \\
\hline \multicolumn{5}{|l|}{ Cardiopulmonary resuscitation (CPR) } \\
\hline Schools trained staff & $86(91)$ & $32(100)$ & $60(63)$ & $178(80)$ \\
\hline Schools trained students & $62(65)$ & $25(78)$ & $27(28)$ & $114(51)$ \\
\hline \multicolumn{5}{|l|}{ Automated external defibrillation (AED) } \\
\hline Schools trained staff & $78(82)$ & $10(31)$ & $16(17)$ & $104(47)$ \\
\hline Schools trained students & $10(11)$ & $1(3)$ & $2(2)$ & $13(6)$ \\
\hline AED present & $79(83)$ & $10(31)$ & $17(18)$ & $106(48)$ \\
\hline AED registered with local EMS dispatch* & $57(72)$ & $6(60)$ & $13(76)$ & $76(72)$ \\
\hline
\end{tabular}




\begin{tabular}{|lcc|}
\hline Table 3. Main teaching methods* & & \\
\hline Method & Student training (\%) & Staff training (\%) \\
\hline Video presentation & 11 & 12 \\
Slide show & 6 & 6 \\
Didactic speaker & 30 & 29 \\
Web/computer & 0 & 1 \\
Interactive & 32 & 31 \\
Training books/written materials & 16 & 15 \\
Unknown & 5 & 6 \\
\hline *Data represented as \% of schools reporting this method and some schools reported more than one method was employed.
\end{tabular}

most commonly employed, and few schools are using cost- and time-effective alternatives that have been demonstrated to be efficacious in adults, such as videoled self-instruction.

Major barriers to training students were noted to be cost and student population size (too small to be worth doing or too large to be logistically possible). A potential solution to this could be implementing alternative training methods such as computer- and video-based instruction. These methods can provide training that is much faster, more frequent, cost-effective, and easily disseminated to a large number of students. ${ }^{26}$ One such alternative is video self-instruction, which employs a "practice-as-you-watch" method where the student watches a 30-minute video and practices compressions on a small mannequin. ${ }^{31}$ This alternative is currently available for around $\$ 30.00 \mathrm{CAD}^{32}$ and has been shown to be as effective as standard basic life support instruction in terms of performance and retention of skills. ${ }^{21,26,31,34-38}$ Future studies could look at the effectiveness of video self-instruction as an online resource in overcoming barriers such as cost and accessibility due to student population size.

The cost of implementing a traditional CPR and AED lay rescuer program has been estimated to be $\$ 3,065$ (USD) per school per year. ${ }^{39}$ Estimates for implementing school-wide video, Web-based, or self-directed learning have not been thoroughly assessed but can be estimated based on the cost of the kit ( $\$ 30.00$ per student). It can be assumed that some costs included in estimates for standard training would be eliminated. These costs include the cost of maintaining and upgrading mannequins, training teachers to be instructors, and hiring substitute teachers to cover for this period of instruction. These less intensive teaching options allow more students to be trained and could help reduce negative attitudes toward CPR and AED training. ${ }^{27}$ More importantly for the community, students are able to take home the training tool and the digital recording and teach, on average, three members of their family and friends. This has widespread public health implications beyond the classroom and may increase the community survival rate through more bystander-initiated resuscitations.

Teaching CPR and AED skills specifically to high school students may have important social ramifications. Potts and Lynch showed that $44.7 \%$ of people in the community stated that they "don't have the time to take a course" and $34.2 \%$ stated that it is "not important" or they "don't care." ${ }^{3} 3$ Teaching CPR and AED skills in high schools can partially address these barriers and help reshape perceptions toward a more helping attitude. High school students have been shown to be more responsive and receptive to CPR training than other groups. ${ }^{40}$ Some have suggested that beginning training around the sixth or seventh grade is better ${ }^{41}$ where kids as young as 10 or 11 years old are capable of performing CPR after training. ${ }^{42}$ Regardless of teaching method, CPR training increased participant confidence, perceived competency, and willingness to help. ${ }^{43}$ Merely testing skills leads to a higher retention of knowledge; thus, incorporating testing into simple training programs may be useful. ${ }^{44}$

The reported rates of CPR and AED instruction suggest that alternative strategies are needed to ensure that all schools are compliant with the legislated curriculum and more students are learning CPR and AED skills. In general, government legislation has been shown to be an effective method of initiating programs and affecting community lay responder rates ${ }^{45,46}$; however, our results show that $49 \%$ of the schools surveyed were noncompliant with the curriculum set by the Ontario Ministry of Education. Future investigations may focus on why certain Toronto high 
schools are not fulfilling the legislated curriculum and what measures and supports are in place to ensure that the curriculum is delivered. In the United States, such policies and programs have increased the number of AEDs in public and private locations. ${ }^{45}$ In Sweden, long-term mass implementation of effective CPR training programs showed an increase in bystander CPR rates from 31 to $55 \% .{ }^{46}$

Dispatch-assisted CPR has been shown to increase bystander CPR rates and can improve CPR quality., ${ }^{1,47}$ In addition, the registration of AEDs will enable EMS dispatchers to locate and direct callers to a nearby AED and coach them to use it with success similar to what they have had coaching bystanders to perform CPR. Twenty-five percent of the AEDs in schools were unregistered, and as a consequence of this study, this link with dispatch and the AED has been established. This should be true for all AEDs regardless of location. AED registration has been linked with higher survival rates ${ }^{48}$ as a shock is more likely to be delivered with guidance from an EMS dispatcher. ${ }^{49}$ AEDs are user-friendly, and there is evidence showing that even untrained first-time users can successfully apply an AED and deliver a shock. ${ }^{50}$

Charitable organizations and the provincial government are in the process of procuring funding for AEDs in schools. As of June 30, 2010, the Heart and Stroke Foundation of Ontario has deployed 2,262 AEDs in the province ${ }^{51}$ and The Mikey Network has committed over 800 AEDs. ${ }^{52}$ The ACT Foundation has funded CPR education for 1.4 million students and new hybrid CPR and AED training for 27,000 students. ${ }^{53}$ In April 2010, a new provincial bill, Bill 41 or The Defibrillator Access Act, was introduced. If passed, it would require the installation of AEDs in places frequented by the public throughout the province, including schools. ${ }^{54}$

Our study has some limitations. The majority of surveys were conducted during June and early July when schools were preparing to close for the summer or moving into examinations and summer programs. This may have reduced response rates, requiring frequent calls to identify the key individual for the interviews. In some cases, due to the lack of comprehensive training programs in schools, data were collected from several different individuals at the same school. The use of a standardized Web-based data entry system ensured the same questions for each school regardless of the number of respondents. The survey contained open-ended qualitative questions that were subject to interviewer and interviewee interpretation and may be limited by interviewee recall bias. This was controlled for by asking all interviewers to record the responses verbatim, providing rigorous training and quality assurance review based on listening in real time to a random sample of calls for each interviewer. The Web-based data abstraction system was limited to the data without source verification as audio recordings and transcriptions of telephone interviews were not done due to cost limitations. The use of point-of-entry error, cross form, and logic checks may have been helpful in minimizing data entry errors.

\section{CONCLUSIONS}

Bystander CPR and AED rates of use are low in Toronto and are the primary predictors of survival from out-of-hospital cardiac arrest. School-based programs have the potential to address this gap in performance by the lay public. Legislated curriculum includes CPR training at a minimum; however, this study found that not all schools in Toronto were reporting compliance with the curriculum. Of the Toronto high schools that were compliant with the curriculum, the majority were noted to use traditional teaching styles with few schools using alternative methods such as Web-based or video instruction. Perceived barriers to CPR and AED training were noted to be cost and student population size (perceived to be either too small to be cost-effective or too large to be implemented). A possible solution to this could be implementing more cost-effective, selfdirected Web-based or DVD-based courses without compromising the quality or retention of CPR training. They may also have the added benefit of informing family and friends when students bring home the learning kit. Future investigations should explore why certain Toronto high schools are not fulfilling the legislated curriculum and what measures and supports are in place to ensure that the curriculum is delivered. The proportion of high schools surveyed providing education on AED use and ensuring that their AEDs were registered with local EMS dispatch was low. The installation and registration of AEDs should also be mandated to provide universal access, better training, familiarity, and school readiness for cardiac arrest. Charitable groups would be advised to target all schools for AED placement. 
Acknowledgements: Cooperation and assistance were received from the Toronto District School Board (Chris Broadbent and Andrea Carlson), the Toronto Catholic District School Board (Nelli Domingues and Anthony Pettiti), and Toronto Emergency Medical Services (Sheryl Jackson). Reference information was provided by The ACT Foundation and interviews with Rachel Cameron, The Mikey Network, and Rescu research staff: Mihai Borcan, Darko Giacomini, Anushia Hasan, Brian Lo, Jevin So, Jinyang Song, Nure Tamann, Cathy Zhan, and Farheen Wani.

Competing interests: This project was funded by the St. Michael's Hospital and Keenan Research Centre Summer Student Program, Sunnybrook Research Institute, and Rescu. Dr. Laurie Morrison has career support from the National Institutes of Health through the Resuscitation Outcomes Consortium and has peer-reviewed research grants in this content area from the American Heart Association and Laerdal Medical Foundation. She is also the past chair of the Heart and Stroke Foundation of Canada Research Policy and Planning Advisory Committee and a volunteer member of the Advance Life Support subcommittee of the Emergency Cardiac Care committee of the American Heart Association. Steve Brooks has a young investigator career support award from the Heart and Stroke Foundation of Canada.

\section{REFERENCES}

1. Vaillancourt C, Stiell IG. Cardiac arrest care and emergency medical services in Canada. Can 7 Cardiol 2004;20:1081-90.

2. Nichol G, Thomas E, Callaway CW, et al. Regional variation in out-of-hospital cardiac arrest incidence and outcome. FAMA 2008;300:1423-31, doi:10.1001/jama.300. 12.1423 .

3. Weisfeldt ML, Sitlani CM, Ornato JP, et al. Survival after application of automatic external defibrillators before arrival of the emergency medical system: evaluation in the resuscitation outcomes consortium population of 21 million. 7 Am Coll Cardiol 2010;55:1713-20, doi:10.1016/j.jacc.2009. 11.077 .

4. Breckwoldt J, Schloesser S, Arntz HR. Perceptions of collapse and assessment of cardiac arrest by bystanders of out-of-hospital cardiac arrest (OOHCA). Resuscitation 2009; 80:1108-13, doi:10.1016/j.resuscitation.2009.06.028.

5. 2005 American Heart Association guidelines for cardiopulmonary resuscitation and emergency cardiovascular care. Circulation 2005;112(24 Suppl):IV1-203.

6. Heart and Stroke Foundation of Canada. Chain of Survival. c2010. Available at: http://restart.heartandstroke.ca/chainsurvival.

7. Gallagher EJ, Lombardi G, Gennis P. Effectiveness of bystander cardiopulmonary resuscitation and survival following out-of-hospital cardiac arrest. FAMA 1995;274:19225, doi:10.1001/jama.1995.03530240032036.

8. Herlitz J, Ekstrom L, Wennerblom B, et al. Effect of bystander initiated cardiopulmonary resuscitation on ventricular fibrillation and survival after witnessed cardiac arrest outside hospital. Br Heart 7 1994;72:408-12, doi:10.1136/ hrt.72.5.408.
9. Herlitz J, Svensson L, Holmberg S, et al. Efficacy of bystander CPR: intervention by lay people and by health care professionals. Resuscitation 2005;66:291-5, doi:10.1016/ j.resuscitation.2005.04.003.

10. Larsen MP, Eisenberg MS, Cummins RO, et al. Predicting survival from out-of-hospital cardiac arrest: a graphic model. Ann Emerg Med 1993;22:1652-8, doi:10.1016/S0196-0644 (05)81302-2.

11. Rea TD, Eisenberg MS, Culley LL, et al. Dispatcherassisted cardiopulmonary resuscitation and survival in cardiac arrest. Circulation 2001;104:2513-6, doi:10.1161/ hc4601.099468.

12. Stiell IG, Wells GA, Field B, et al. Advanced cardiac life support in out-of-hospital cardiac arrest. N Engl 7 Med 2004; 351:647-56, doi:10.1056/NEJMoa040325.

13. Waalewijn RA, Tijssen JG, Koster RW. Bystander initiated actions in out-of-hospital cardiopulmonary resuscitation: results from the Amsterdam Resuscitation Study (ARRESUST). Resuscitation 2001;50:273-9, doi:10.1016/ S0300-9572(01)00354-9.

14. Van Hoeyweghen RJ, Bossaert LL, Mullie A, et al. Quality and efficiency of bystander CPR. Belgian Cerebral Resuscitation Study Group. Resuscitation 1993;26:47-52, doi:10.1016/0300-9572(93)90162-J.

15. Wik L, Steen PA, Bircher NG. Quality of bystander cardiopulmonary resuscitation influences outcome after prehospital cardiac arrest. Resuscitation 1994;28:195-203, doi:10.1016/0300-9572(94)90064-7.

16. Valenzuela TD, Roe DJ, Nichol G, et al. Outcomes of rapid defibrillation by security officers after cardiac arrest in casinos. N Engl 7 Med 2000;343:1206-9, doi:10.1056/NEJM 200010263431701.

17. Swor R, Khan I, Domeier R, et al. CPR training and CPR performance: do CPR-trained bystanders perform CPR? Acad Emerg Med 2006;13:596-601, doi:10.1111/j.15532712.2006.tb01017.x.

18. Axelsson A, Herlitz J, Ekstrom L, et al. Bystander-initiated cardiopulmonary resuscitation out-of-hospital. A first description of the bystanders and their experiences. Resuscitation 1996;33:3-11, doi:10.1016/S0300-9572(96) 00993-8

19. Abella BS, Aufderheide TP, Eigel B, et al. Reducing barriers for implementation of bystander-initiated cardiopulmonary resuscitation: a scientific statement from the American Heart Association for healthcare providers, policymakers, and community leaders regarding the effectiveness of cardiopulmonary resuscitation. Circulation 2008;117:704-9, doi:10. 1161/CIRCULATIONAHA.107.188486.

20. Olasveengen TM, Wik L, Steen PA. Standard bystander CPR versus continuous chest compressions only in out-ofhospital cardiac arrest. Resuscitation 2008;77:S10, doi:10. 1016/j.resuscitation.2008.03.041.

21. Todd KH, Braslow A, Brennan RT, et al. Randomized, controlled trial of video self-instruction versus traditional CPR training. Ann Emerg Med 1998;31:364-9, doi:10.1016/ S0196-0644(98)70348-8.

22. Vaillancourt C, Stiell IG, Wells GA. Understanding and improving low bystander CPR rates: a systematic review of the literature. CFEM 2008;10:51-65. 
23. Eisenburger $P$, Safar P. Life supporting first aid training of the public-review and recommendations. Resuscitation 1999; 41:3-18, doi:10.1016/S0300-9572(99)00034-9.

24. Lafferty C, Larsen PD, Galletly D. Resuscitation teaching in New Zealand schools. N Z Med 7 2003;116:U582.

25. Lyttle J. Mandatory CPR training for students may improve cardiac-arrest survival rate, MDs say. CMA7 1996;155: $1172-4$.

26. Isbye DL, Rasmussen LS, Ringsted C, et al. Disseminating cardiopulmonary resuscitation training by distributing 35,000 personal manikins among school children. Circulation 2007; 116:1380-5, doi:10.1161/CIRCULATIONAHA.107.710616.

27. Parnell MM, Pearson J, Galletly DC, et al. Knowledge of and attitudes towards resuscitation in New Zealand highschool students. Emerg Med f 2006;23:899-902, doi:10.1136/ emj.2006.041160.

28. Ontario Ministry of Education and Training. Ontario secondary schools - grades 9-12: program and diploma requirements. Toronto: Queen's Printer for Ontario; 1999.

29. Ontario Ministry of Education and Training. The Ontario curriculum - grades 9 and 10: health and physical education. Toronto: Queen's Printer for Ontario; 1999.

30. Lotfi K, White L, Rea T, et al. Cardiac arrest in schools. Circulation 2007;116:1374-9, doi:10.1161/CIRCULATIO NAHA.107.698282.

31. Braslow A, Brennan RT, Newman MM, et al. CPR training without an instructor: development and evaluation of a video self-instructional system for effective performance of cardiopulmonary resuscitation. Resuscitation 1997;34:207-20, doi:10.1016/S0300-9572(97)01096-4.

32. Heart and Stroke Foundation of Canada. CPR anytime. c2007. Available at: https://resuscitation.heartandstroke.ca/ resources/training_materials/CPR_Anytime_Kit (accessed Feb 25, 2013).

33. Potts J, Lynch B. The American Heart Association CPR Anytime Program: the potential impact of highly accessible training in cardiopulmonary resuscitation. 7 Cardiopulm Rehabil 2006;26:346-54, doi:10.1097/00008483-20061100000002.

34. Batcheller AM, Brennan RT, Braslow A, et al. Cardiopulmonary resuscitation performance of subjects over forty is better following half-hour video self-instruction compared to traditional four-hour classroom training. Resuscitation 2000;43:101-10, doi:10.1016/S0300-9572(99) 00132-X.

35. Einspruch EL, Lynch B, Aufderheide TP, et al. Retention of CPR skills learned in a traditional AHA Heartsaver course versus 30-min video self-training: a controlled randomized study. Resuscitation 2007;74:476-86, doi:10.1016/j.resuscitation.2007.01.030.

36. Isbye DL, Rasmussen LS, Lippert FK, et al. Laypersons may learn basic life support in $24 \mathrm{~min}$ using a personal resuscitation manikin. Resuscitation 2006;69:435-42, doi:10.1016/ j.resuscitation.2005.10.027.

37. Roppolo LP, Saunders T, Pepe PE, et al. Layperson training for cardiopulmonary resuscitation: when less is better. Curr Opin Crit Care 2007;13:256-60, doi:10.1097/MCC.0b013e 32814db81f.

38. Todd KH, Heron SL, Thompson M, et al. Simple CPR: a randomized, controlled trial of video self-instructional cardiopulmonary resuscitation training in an African American church congregation. Ann Emerg Med 1999;34: 730-7, doi:10.1016/S0196-0644(99)70098-3.

39. Berger S, Utech L, Hazinski MF. Lay rescuer automated external defibrillator programs for children and adolescents. Pediatr Clin North Am 2004;51:1463-78, doi:10.1016/ i.pcl.2004.04.009.

40. Rosafio T, Cichella C, Vetrugno L, et al. Chain of survival: differences in early access and early CPR between policemen and high-school students. Resuscitation 2001;49:25-31, doi: 10.1016/S0300-9572(00)00341-5.

41. Kelley J, Richman PB, Ewy GA, et al. Eighth grade students become proficient at CPR and use of an AED following a condensed training programme. Resuscitation 2006;71:229 36, doi:10.1016/j.resuscitation.2006.03.015.

42. Hill K, Mohan C, Stevenson M, McCluskey D. Objective assessment of cardiopulmonary resuscitation skills of 10-11year-old schoolchildren using two different external chest compression to ventilation ratios. Resuscitation 2009;80:96-9, doi:10.1016/j.resuscitation.2008.08.005.

43. Lynch B, Einspruch EL. With or without an instructor, brief exposure to CPR training produces significant attitude change. Resuscitation 2010;81:568-75, doi:10.1016/j.resuscitation. 2009.12.022.

44. Kromann CB, Jensen ML, Ringsted C. The effect of testing on skills learning. Med Educ 2009;43:21-7, doi:10.1111/ j.1365-2923.2008.03245.x.

45. Aufderheide T, Hazinski MF, Nichol G, et al. American Heart Association Emergency Cardiovascular Care C, Council on Clinical C, Office of State A. Community lay rescuer automated external defibrillation programs: key state legislative components and implementation strategies: a summary of a decade of experience for healthcare providers, policymakers, legislators, employers, and community leaders from the American Heart Association Emergency Cardiovascular Care Committee, Council on Clinical Cardiology, and Office of State Advocacy. Circulation 2006;113:1260-70, doi:10.1161/CIRCULATIONAHA.106.172289.

46. Strömsöe A, Andersson B, Ekstöm L, et al. Education in cardiopulmonary resuscitation in Sweden and its clinical consequences. Resuscitation 2010;81:211-6, doi:10.1016/ j.resuscitation.2009.10.014.

47. Mirza M, Brown TB, Saini D, et al. Instructions to "push as hard as you can" improve average chest compression depth in dispatcher-assisted cardiopulmonary resuscitation. Resuscitation 2008;79:97-102, doi:10.1016/j.resuscitation.2008.05.012.

48. Myers JB, French D, Webb W. Lack of integration of automated external defibrillators with EMS response may reduce lifesaving potential of public-access defibrillation. Prehosp Emerg Care 2005;9:339-43, doi:10.1080/109031 20590961969

49. Ecker R, Rea TD, Meischke H, et al. Dispatcher assistance and automated external defibrillator performance among elders. Acad Emerg Med 2001;8:968-73, doi:10.1111/j.15532712.2001.tb01096.x.

50. Caffrey SL, Willoughby PJ, Pepe PE, et al. Public use of automated external defibrillators. $N$ Engl 7 Med 2002;347: 1242-7, doi:10.1056/NEJMoa020932.

51. The Heart and Stoke Foundation of Ontario. Restart. 2010. Available at: https://resuscitation.heartandstroke.ca/ (accessed Feb 23, 2013). 
52. The Mikey Network. About The Mikey Network. c2010. Available at: http://mikeynetwork.com/mikey-defibrillators (accessed Feb 23, 2013).

53. ACT Foundation of Canada. Ontario high school students give MPPs a lesson in lifesaving [press release]. February 24, 2010.
Available at: http://actfoundation.ca/wp-content/uploads/2012/ 10/act-Media-Releases-Archive-2010-PressRelease-ForWeb.pdf (accessed Feb 25, 2013).

54. An Act to provide for defibrillators in premises accessed by members of the public, Bill 41, 39th Legislature, 2nd Session (2010). 